\title{
Grupos áulicos: aprendendo com os pares
}

\author{
Nair Cristina da Silva Tuboiti \\ Secretaria de Educação do Distrito Federal - Brasília - DF \\ Lêda Gonçalves de Freitas \\ Universidade Católica de Brasília - Brasília - DF
}

\section{Resumo}

Este estudo visa evidenciar as contribuições dos grupos áulicos no processo de aprendizagem entre pares. Pressupõe-se que grupos áulicos garantem o espaço relacional na perspectiva multidirecional. A coleta de dados foi realizada em uma turma de $1^{\circ}$ ano do Ensino Fundamental de uma escola pública de Samambaia, Distrito Federal, por meio de observação participante, entrevista não estruturada e análise documental. Os dados foram analisados na perspectiva sociocultural em diálogo com a teoria interpretativa de Geertz. Os resultados indicam que os grupos áulicos permitem reorganizar o pensamento fazendo diferença no campo do ensino e aprendizagem, na perspectiva de um espaço que possibilite a diversidade de relações, rompendo com as profecias de fracasso e instaurando um lugar real do aluno nessa relação de construção de conhecimentos. A interlocução entre os pares ocorre no grupo heterogêneo que possibilita que se aprendam conceitos com os diferentes saberes, afinal aprende-se em meio à diversidade.

Palavras-chave: Grupos; aprendizagem; ensino.

\section{Groups courtiers: learning from the pair}

\begin{abstract}
This study aims to highlight the contributions of courtiers groups in the process of peer learning. It is assumed that courtiers groups guarantee the relational space in multidirectional perspective. Data collection was carried out in a class of 1st year of elementary school to a public school in Samambaia, Federal District, through participant observation, unstructured interview and document analysis. Data were analyzed in the sociocultural perspective in dialogue with the interpretive theory of Geertz. The results indicate that the courtiers groups allow reorganizing the thinking towards making a difference in teaching and learning field with a view to a space that allows the diversity of relationships, breaking with the failure of prophecies and establishing a real student's place in that relationship construction of knowledge. The dialogue between the pairs occurs in the heterogeneous group that makes it possible to learn concepts with different knowledge, after learning in the midst of diversity.
\end{abstract}

Keywords: Groups; learning; teaching.

\section{Grupos áulicos: aprendiendo con los pares}

\section{Resumen}

Este estudio tiene por objetivo evidenciar las contribuciones de los grupos áulicos en el proceso de aprendizaje entre pares. Se presupone que grupos áulicos garantizan el espacio relacional en la perspectiva multidireccional. La recolecta de datos fue realizada en un grupo de 1er año de la Enseñanza Fundamental de una escuela pública de Samambaia, Distrito Federal, por intermedio de observación participante, entrevista no estructurada y análisis documental. Los datos fueron analizados en la perspectiva sociocultural en diálogo con la teoría interpretativa de Geertz. Los resultados indican que los grupos áulicos permiten reorganizar el pensamiento trayendo diferencia en el campo de la enseñanza y aprendizaje en la perspectiva de un espacio que posibilite la diversidad de relaciones, rompiendo con las profecías de fracaso e instaurando un lugar real del alumno en esa relación de construcción de conocimientos. La interlocución entre los pares ocurre en el grupo heterogéneo que posibilita que se aprendan conceptos con los diferentes saberes, a final se aprende en medio a la diversidad.

Palabras-clave: Grupos; aprendizaje; enseñanza. 


\section{Introdução}

O termo 'áulico' é derivado de 'aula', conforme expressam Abatti, Villas-Boas e Cabral (2010). Neste sentido, 'grupos áulicos' diz respeito a um procedimento de organização dos alunos na sala de aula focado nas aprendizagens de todos, procedimento este discutido e inserido nas turmas do Grupo de Estudos sobre Educação, Metodologia de Pesquisa e Ação (Geempa¹) desde 1975.

Diante de uma educação individualista e na perspectiva de validar a premissa de que se aprende com o outro na situação escolar, o Geempa, ao longo da sua trajetória de pesquisa, redefiniu a estética da sala de aula ao organizá-la em grupos heterogêneos constituídos em função das aprendizagens. Essa prática teve origem na experiência vivida pelo psicanalista José Luiz Caon. Em 1965, Caon era professor em Lajes, Santa Catarina, e percebeu, nas atividades desportivas, como era desigual a constituição dos times, sendo sempre um mais forte que o outro. Isto o levou a pensar formas diferentes de se produzir times mais equilibrados até chegar à organização dos grupos por meio da eleição (Caon, 2010).

Assim sendo, os grupos áulicos são formações em grupos para que os alunos aprendam. A formação dos grupos se dá por meio de uma eleição democrática que define líderes para bem articular as atividades em cada grupo. Neste sentido, os alunos votam em três colegas, sabendo que todo procedimento se dá por meio da escolha pautada no desejo de aprender, considerando com quem eu quero aprender, com quem eu quero trocar e a quem eu quero ensinar. Ao definirem os líderes, por meio dessa votação, na sequência, um a um vai convidando os demais colegas a pertencerem ao próprio grupo.

De acordo com a quantidade de alunos na turma, definem-se quantos grupos formar-se-ão. Esses grupos devem ser, preferencialmente, constituídos por 4 (quatro) componentes. O que mais importa é ter clareza da qualidade do grupo em função das aprendizagens. A cada bimestre esta configuração é modificada por meio de nova eleição, portanto oportuniza novas lideranças, uma diversidade de interações.

Cabe salientar que os grupos áulicos se configuram em uma experiência específica do Geempa, ONG que tem uma ampla experiência em alfabetização de crianças. Portanto, este artigo não traz estudos sobre a prática deste procedimento didático, uma vez que não foram encontradas pesquisas sobre a referida temática. O propósito do presente artigo consiste em evidenciar as contribuições dos grupos áulicos no processo de aprendizagem entre pares. O pressuposto básico é de que os grupos áulicos garantem o espaço relacional na perspectiva multidirecional, de forma que todos se percebam envolvidos e aprendendo com seus

1 O Geempa (Grupo de Estudos sobre Educação, Metodologia de Pesquisa e Ação) é uma organização não governamental que, desde 1970, vem estudando, pesquisando e atuando na área da educação, com ênfase na alfabetização e na formação do professor (Rocha, 2000). pares por meio de intervenções que consideram a riqueza sociocultural, em direção à democratização do saber.

\section{Os grupos áulicos}

A sala de aula é um microcosmo da sociedade (Rocha, 2005), lócus onde o sujeito que aprende passa parte do seu cotidiano imerso em uma teia de novas relações. É um contexto social com condições para oportunizar experiências de aproximação e de distanciamento, vincula tempo e espaço que, de alguma forma, provoca reflexões e transformações.

O primeiro momento se dá na aula-entrevista ${ }^{2}$ por meio da exibição de alguns gráficos de escadas ${ }^{3}$ para que os alunos tomem conhecimento das suas hipóteses quanto à leitura e à escrita. Este procedimento visa uma ação didática que vá ao encontro do processo do aluno, com a intenção de acolher ou de romper com seu pensamento rumo à meta de, ao final do ano, ler e escrever um texto simples com compreensão.

Os gráficos de escadas apresentados anteriormente à eleição e à constituição dos grupos áulicos são referentes a três tarefas da aula-entrevista: o gráfico da leitura do nome, o da escrita das quatro palavras e de frase e o do conhecimento de letras. O objetivo de apresentá-los é para que os alunos percebam a si e aos colegas nos diferentes processos de aprendizagem e, assim sendo, realizem uma votação ao expressar o desejo de aprender com os diferentes saberes. O professor orienta os alunos quanto às regras da eleição, quanto ao papel do coordenador e suas atribuições para que, com entusiasmo, articule o bom funcionamento do grupo. As regras são definidas em um diálogo com a turma, a ponto de constituírem um contrato didático, orientado pelo professor, com as devidas intervenções e encaminhamentos.

Nesse contexto, primeiramente, cada aluno escreve em uma cédula os nomes de três colegas com os quais deseja aprender, trocar conhecimento e a quem gostaria de ensinar. Na apuração dos votos, em um quadro em que os nomes dos alunos estão relacionados, registram-se os votos. O primeiro nome recebe um peso de 3 pontos, o segundo de 2 e o terceiro de 1. Prossegue-se, então, contabilizando todos os votos. Cada aluno calcula sua pontuação e a informa ao professor à medida que é solicitado (na impossibilidade de realizar a contagem, os colegas certamente auxiliam uns aos outros).

2 Encontro entre professor e aluno em que são realizadas dez tarefas para diagnosticar a zona de aprendizagem do aluno quanto à escrita e à leitura do próprio nome, de letras, de palavras, de textos e as unidades linguísticas. Possibilita que se conheça o aluno na perspectiva das questões socioculturais e subjetivas (Geempa, 2010).

3 São gráficos em forma de escadas que apresentam, para a turma, o processo de aprendizagem de cada aluno quanto à leitura e à escrita de letras, de palavras, de textos e as unidades linguísticas, eixos que constituem a zona proximal de aprendizagem da leitura e da escrita, caracterizados com base na aula-entrevista (Geempa, 2010). Tais esquemas são fixados na sala para que o aluno visualize e seja sensibilizado à construção de novas aprendizagens. 
Depois que todos os alunos anunciam as respectivas pontuações, define-se, neste momento, quem e quantos são os líderes de acordo com a maior pontuação e o número total de alunos na turma na perspectiva de se ter quatro alunos em cada grupo. No caso de empate, é possível desempatar pelo peso dos votos ou de acordo com a sugestão da turma. Diante dessa definição, os eleitos vão à frente para convidarem os demais componentes a participarem do seu grupo, podendo ser aceitos ou não. O mais votado convida primeiro; continua na sequência dos que mais receberam votos até chegar ao último coordenador. $\mathrm{Na}$ ordem inversa, do último para o primeiro, a dupla convida um terceiro colega para participar do seu grupo, com direito a aceitar ou não. Por que assim? Com o objetivo de que os melhores não fiquem apenas em um "time", mas que haja uma proporção mais justa (Caon, 2010).

Os alunos que ficarem por último têm o direito de escolher o grupo para o qual desejam ir. Neste caso, os grupos já constituídos de três componentes definem uma apresentação, demonstrando, com criatividade, o que os colegas ganham ao participar daquele grupo. Depois que os trios se apresentam, os alunos que ainda não têm grupo se dirigem, um a um, para o grupo ao qual desejam integrar-se, podendo ser aceitos ou não. É importante deixar bem claro que se tem liberdade para aceitar ou não o convite que lhes é feito. As regras devem ser bem definidas, esclarecendo que todos têm de pertencer a um grupo. Além disso, uma vez aceito o convite, não poderá haver troca de grupo antes da próxima eleição. Os grupos permanecem com a mesma constituição por um bimestre, quando serão realizadas novas eleições, o que acontece por volta de quatro vezes ao longo de um ano letivo.

Após esta organização, cada grupo escolhe o lugar em que deseja ficar na sala, na lógica de pensar o território a que pertencem. Organizam-se, dialogam e escolhem um nome significativo para todos os componentes, podendo ser identificados. É importante trazer à tona os sentimentos vividos ao longo desta trajetória, expressos, tanto pela escrita, quanto pela oralidade, ao se tornar possível que os alunos falem e conversem claramente sobre eles. Há uma merenda pedagógica ${ }^{4}$ que simboliza este momento: um grupo entrega o lanche para outro, trabalhando os laços sociais. Em seguida, realizam uma atividade que permite que se constituam como grupo ao realizar uma construção que signifique aprendizagem.

A organização dos grupos áulicos prima, portanto, pela interação entre estudante-estudante, numa dinâmica de posicionar o sujeito que aprende em constante relação

\footnotetext{
4 No pós-construtivismo, a merenda é vista como uma atividade pedagógica. Muitas atividades didáticas podem originar-se a partir dela. Realiza-se na turma de diversas maneiras. No caso do dia da organização da turma em grupos áulicos, um grupo entrega o lanche para outro dizendo o porquê. O grupo que recebe a merenda por primeiro reserva-o no seu lugar; toma outra porção, oferece-a a outro, de acordo com a escolha do grupo, e assim sucessivamente até que todos estejam servidos e possam dar início à merenda. Esse procedimento fica registrado por meio de um sociograma, que também se torna uma atividade didática (Rocha, \& Vedana, 2010).
}

com as diferentes formas de aprender presentes em uma turma. É o tipo de organização que permite, aos alunos, estabelecer relações de alteridade no contexto da diversidade sociocultural. Desse modo, contribui para que o sujeito construa sua história com base em situações de confronto e de colaboração, em circunstâncias sociais favoráveis à aprendizagem e à negociação. Não se trata de mais uma atividade, mas de um princípio didático fundamental para o sucesso e a qualidade das aprendizagens.

\section{3. $O$ aprender e sua complexidade}

Piaget (1896-1980), psicólogo suíço, compreende que aprender perpassa pela interação entre o sujeito e a realidade, em uma relação biunívoca na qual o sujeito sai de um lugar de passividade e passa a ser sujeito ativo na construção do próprio conhecimento. Os estudos de Piaget se concentram no sujeito que interage com a realidade para conhecer como este opera com o real. Para que haja esse movimento, Piaget (2004) afirma que deve haver um motivo, uma manifestação de desequilíbrio, uma necessidade inclinada a um movimento de equilibração, de assimilação e de acomodação; equilíbrio no sentido de avançar com base em um pensamento anterior; assimilação no sentido de adaptar as novas experiências às que já se possui; e acomodação no sentido de modificar o esquema existente.

O exercício dessa ação pressupõe uma organização mental, o que é evidenciado por Piaget (1983) ao analisar que o desenvolvimento intelectual se dá em grandes estágios: sensório-motor (do nascimento até os dois anos), pré-operatório (2 a 7 anos), operações concretas ( 7 anos até a adolescência) e operações formais (adolescência até a fase adulta). Piaget esclarece, ainda, que esses estágios não são restritos a um período cronológico, tendo em vista a inserção social do sujeito, que pode acelerar, retardar ou impedir a presença desses estágios.

Em cada estágio, Piaget observou que a criança desenvolve estruturas mentais, perfazendo um procedimento sequencial e apresentando maneiras distintas de compreender e de resolver situações-problema. Assim, Piaget e Grêco (1974, p. 40) afirmam que "a aprendizagem é um processo adaptativo se desenvolvendo no tempo, em função das respostas dadas pelo sujeito a um conjunto de estímulos anteriores e atuais". Logo, os estudos de Piaget contribuem ricamente com o pensamento pedagógico, pois oportunizam uma compreensão minuciosa do sujeito que constrói conhecimentos e permite ao professor refletir sobre o seu fazer didático e pedagógico.

No mesmo período em que Piaget, mas em outro contexto, Wallon (1995) argumenta que não é possível estudar a criança como um ser fragmentado, nem mesmo como uma soma de funções na perspectiva de continuidade, mas como um processo descontínuo, levando em consideração que o desenvolvimento mental é perpassado pelos domínios funcionais da afetividade, do ato motor e do cognitivo da pessoa, que exercem influência estruturante na formação 
do sujeito por meio da relação dialógica e dialética. Desde o período embrionário, a criança vive etapas específicas. Na passagem de uma para outra, vivencia crises e conflitos seguidos de vestígios do vivido anteriormente, pois uma construção prevê reelaboração, movimento que implica "[...] manifestações antecipadas de uma função, devidas a um feliz concurso de circunstâncias, e regressões, devidas à elaboração ainda insuficiente dos seus factores subjectivos [...]" (Wallon, 1995, p. 111).

Nessa trajetória, as escolhas que o sujeito aprendente faz vêm do encontro com as pessoas, com as coisas e com as instituições às quais se vincula por meio da afetividade e da linguagem. O contexto sociocultural no qual o sujeito aprendente está inserido vai estruturando seu pensamento que, inicialmente, está amalgamado ao pensar do outro. As escolhas vão se constituir por meio de conflitos e são reflexos das constantes interações que se desenrolam no meio em que estão sendo formadas. Neste caso, a aprendizagem que se constrói na interação com o outro é importantíssima para o ser humano, um "[...] animal essencialmente social" (Wallon, 1995, p. 59).

Com essas ideias, Wallon rompe com uma educação direcionada para as potencialidades exclusivamente individuais, pois suas reflexões pressupõem um sujeito integrado a um contexto sociocultural. A aprendizagem deve, portanto, apoiar-se nos aspectos afetivos, cognitivos e motores do sujeito que interage com o outro. Nessa interação com o outro, conforme Wallon (1989), o pensamento estrutura-se em um encadeamento que, muitas vezes, não se coordena na união de temas assimilados e opostos. O pensamento passa pelas fases de condensação e de fragmentação, em um exercício de retenção do que foi dilatado na fase de expansão. Como esse processo não é muito presente na criança, ela se utiliza do recurso de reter o que está nas lembranças ou nas reflexões, operando ao reunir o que é mais evidente.

Enquanto isso, Vygotsky (1994) contribui com seus estudos ao pensar o ser humano inserido em uma cultura em que, ao relacionar-se com o meio físico e social, vai internalizando modos de interatividade. Nesta concepção é ativo; suas aprendizagens são construídas na interação com o objeto e com os outros com os quais convive. Neste processo de interação, a mediação se dá pelo uso de instrumentos e de signos. Os instrumentos são externos, construídos pelos humanos com base em suas próprias necessidades. Por exemplo: para se alimentar, utiliza-se de talheres; para escrever, de lápis, de caneta, de computador. O signo, por sua vez, é uma marca interna, porém orientado para o próprio sujeito. Representa a concretização das soluções dos problemas de comunicação. O gesto é o primeiro signo no exercício da comunicação. Ao fazer um estudo filogenético, é no gesto de apontar que Vygotsky (1994) demonstra a função de internalização, movimento que o sujeito faz no sentido de se apropriar do que é percebido nas relações. Do mesmo modo, o homem vai construindo a linguagem que se expressa na fala e que tem como função a comunicação. A fala se constitui egocêntrica e significativa, o que tem um papel importante na atividade da criança.
$\mathrm{Na}$ comunicação, a construção do pensamento e da linguagem se reveste de grande complexidade. A linguagem que abre caminho para toda a produção cultural, artística e simbólica de um sujeito e para si mesmo depende de fatores externos. O pensamento que passa pelo significado e, depois, pelas palavras, nas quais encerra desejos, necessidades, interesses, emoções e compreensões depende dos meios sociais. Neste sentido, importa compreender que o pensamento verbal não é inato, mas tem um caráter histórico-social e se estabelece em um contexto sociocultural. "[...] a linguagem primordial da criança é puramente social [...]" (Vigotsky, 2000, p. 63).

A organização dos grupos áulicos tem como referência as ideias de Piaget, Wallon e Vigotsky para que a prática docente promova a potencialidade de todos os sujeitos cognoscentes, com um profissional que atua na cena áulica para formar sujeitos pensantes e questionadores, pois "saber é um processo, não um produto" (Bruner, 1975, p. 75).

Acentua-se que o ambiente áulico, rico em aprendizagens, permite a cada aluno perceber-se, compreender-se na relação com o outro, assumir diferentes papéis sociais refletindo sobre questões de pertencimento e de identidade vinculados ao ensino e à aprendizagem. Neste sentido, por meio dos grupos áulicos, possibilita-se, ao sujeito, a experiência da vida em sociedade, iniciando-se, conscientizando-se e exercitando-se para a vida em sociedade.

\section{A pesquisa realizada}

A pesquisa realizada utilizou-se da abordagem qualitativa, que pressupõe "considerar o pesquisador como o principal instrumento de investigação e a necessidade de contato direto [...] com o campo, para poder captar os significados dos comportamentos observados" (Alves-Mazzotti, 2002, p. 132).

A pesquisa ocorreu em uma escola pública do Distrito Federal - DF, pertencente à Coordenação Regional de Ensino de Samambaia (CRESam), em uma turma de $1^{\circ}$ ano do Ensino Fundamental de 9 anos. Tal escolha se deu em função de a professora dessa turma trabalhar com grupos áulicos, objeto desta investigação.

A turma pesquisada era composta por 17 alunos, entre meninos e meninas na faixa etária entre 6 e 7 anos provenientes de famílias de baixa renda, de um ambiente sociocultural com algumas restrições de acesso a atividades culturais como cinema, teatro, livrarias, apresentações musicais, exposições artísticas. Todos nasceram no DF, em diferentes cidades.

$\mathrm{Na}$ época desta pesquisa, a professora da turma tinha 34 anos, era casada, tinha uma filha de 15 anos e residia no Guará, cidade-satélite do DF. Atua na Secretaria de Educação do DF com carga horária de 40h semanais, sendo 25 horas com os alunos no turno vespertino e 15 horas no turno matutino destinado para estudo e planejamento. Formada em pedagogia, com especialização em psicopedagogia, continuou sua formação profissional com base nas 
elaborações científicas do Geempa, o que provocou muitas desconstruções de suas concepções pedagógicas nos últimos anos de atuação em sala de aula.

Os instrumentos de coleta de dados foram a observação participante, que foi registrada pelo diário de campo, a análise documental e a entrevista não estruturada. A análise dos dados iniciou-se pela leitura de todo o material, na busca por significados que emergissem das falas como atribuições dos sujeitos a suas próprias ações, sem categorizá-las, a priori, e de forma a auxiliar as interpretações a serem discutidas teoricamente, tomando por base e direcionamento os objetivos desta pesquisa, com a compreensão de que "as sociedades, como as vidas, contêm suas próprias interpretações. É preciso apenas descobrir o acesso a elas" (Geertz, 1978, p. 321).

\section{Resultados: grupos áulicos - aprender com os pares numa lógica heterogênea}

Os resultados indicam que os grupos áulicos permitem reorganizar o pensamento rumo a fazer diferença no campo do ensino e da aprendizagem, na perspectiva de um espaço que possibilite diversidade de relações, rompendo com as profecias de fracasso e instaurando um lugar real para o aluno nessa relação de construção de conhecimentos. Rompe-se, ainda, com a configuração que, simbolicamente, marca o tradicional lugar do professor como detentor do saber, como aquele que ensina, que transmite e que mantém uma relação centrada nele mesmo, marcada pelo individualismo e por relações limitadas.

Nos grupos áulicos, tanto a autonomia dos alunos, quanto o papel da professora que coordena a cena áulica com provocações se concretizam. Primeiro, porque ensinar perpassa por criar situações e procedimentos para que o outro se aproprie de um conhecimento pensando. Para isso, é necessário que se aprenda como fazê-lo; segundo, importa que se tenha consciência de que tudo isso diz respeito a um plano que envolve os outros e se sustenta na construção da relação didática e pedagógica. Uma situação observada na turma da professora nos ajuda a pensar esta questão:

Os alunos estavam escrevendo um texto sobre um filme a que assistiram; uma maneira sugerida pela professora para que Ihe contassem a história do filme, pois eles assistiram com outra turma e ela não estava presente. No momento da escrita, observa-se que, ao mesmo tempo em que todos trabalham, eles vão conversando amenidades do dia a dia. De repente, estão envolvidos com suas escritas e percebe-se uma discussão no grupo Aprender a ler e escrever. Observa-se que M.L. solicita ao grupo ajuda. C.S. pergunta 'Em quê?' M.L. responde: 'Como escrevo a palavra filme?' A.R. se antecipa e pede para ela escutar quando fala pausadamente: 'FIL - Ml'. Pensa quais as letras... M.L. percebe I U M. A.R. diz: 'vou repetir de novo: 'FIL - MI. Você não percebe as outras letras? FIL começa com F, e MI termina com I, FILMI'. Esta discussão chamou a atenção dos demais colegas, entre eles, o D.S., que estava mais distante na sua concepção de escrita em relação a M.L. (Diário de Campo, 1/9/2011).

$\mathrm{Na}$ situação acima, as crianças, em diferentes processos do conhecimento, conversam, pensam, discutem sobre a escrita de uma palavra na construção do texto e definem em conformidade com o que pensam. Com essa estrutura norteadora, ficou claro o quanto a organização da aula em grupos áulicos faz com que a professora garanta espaço para que os estudantes sejam autônomos, ao resolver, entre si, as situações didáticas ou não. Assim, aprender entre pares é perpassado por uma relação que permite rupturas e novas concepções, direcionando os aprendizes a um novo fazer, neste caso, no universo da leitura e da escrita.

O fato de as aprendizagens serem elaboradas na relação entre pares desconstrói a ideia de que, para ensinar, tem-se de ser detentor de um saber. Entretanto, o que mais importa são as maneiras, a arte do fazer, as intervenções baseadas no processo de cada aluno, o que implica na qualificação desse profissional. Sabemos, porém, que essa qualificação não se limita ao saber lógico, ao conteúdo, mas se abre para o novo, centrado na complexidade do sujeito que pensa e cujo saber passa a ser valorizado; viabiliza, portanto, que o ensino e a aprendizagem se deem na lógica multidirecional. Dessa forma, os envolvidos contribuem para que haja apropriação do conhecimento por todos (Rogoff, 2005). É o que relata a professora:

Para que o trabalho em grupo aconteça, eu tenho conhecimento do processo do aluno por meio da aulaentrevista. Então, o grupo e a aula-entrevista são ações que me permitem articular para que o saber circule, o que se dá ao jogarem, trocarem, e os que não aprenderam no momento que eu queria, eu consegui deslocar este saber para que aprendessem em outro, como aconteceu! Sem perder de vista que a turma foi inserida, se comprometeu a partir do que eu falei, da situação de todos [processo de aprendizagem de cada um] e, assim, construí o espírito de corresponsabilidade. Envolver a turma permitiu que [as ações] não ficassem só na professora (Transcrição de Entrevista, 9/12/2012).

Ao dividir a responsabilidade com cada aluno, tornando-os corresponsáveis e envolvidos com as questões da turma, e a partir dessa reflexão estruturar as aulas com mais desafios e foco no processo e nas questões subjetivas de cada um, foi possível finalizar o ano letivo com todos lendo e escrevendo um texto simples. Estava garantida, assim, a aprendizagem, reiterando o princípio vigotskiano de que "o movimento real do processo de desenvolvimento do pensamento infantil não se realiza do individual para o socializado, mas do social para o individual" (Vigotski, 2000, p. 67). Nesse cenário, a professora conquista outro lugar que Ihe permite, além de organizar a cena áulica, centrar-se em observar as aprendizagens, o processo de cada aluno e, assim, direcionar melhor as intervenções didáticas. Destarte, 
a organização da sala de aula em grupos áulicos propiciou que a interação entre os estudantes fosse intensificada, permitindo à professora construir corresponsabilidades e envolver a turma no processo de aprendizagem de todos.

$\mathrm{Na}$ prática observada percebe-se que a professora aposta na capacidade de todos; não se coloca no lugar de quem sabe tudo, mas tem clareza das suas limitações e não as torna paralisantes, pelo contrário, criativamente, e em parceria com seus iguais, cria situações para que todos aprendam. Tem, nos grupos áulicos, a oportunidade para que as lideranças circulem; para construir um espírito de cumplicidade entre os alunos com foco nas aprendizagens de todos e para ocupar outro lugar nesse cenário; o lugar de quem coordena a cena áulica para que todos sejam atores nesse espetáculo, pois tem a certeza de que se aprende na relação com o outro, uma vez que todos têm algo a contribuir com a aprendizagem do outro. Assim, ao instaurar a interlocução entre os diferentes saberes, que vai ao encontro da liberdade e da emancipação, há a transformação dos conflitos que configuram um jogo de poder entre professores e alunos (Keil,1995). Desta forma, para que os grupos áulicos alcancem os seus objetivos faz-se necessária uma postura docente de abertura, de diálogo e de ter em mente que o processo de educar requer um contexto de sala de aula em que prevaleça a liberdade e autonomia do estudante.

A organização do espaço, com foco nas relações de ensino e aprendizagem, traz consigo condições para melhor administrar o pensamento que encaminha o fazer pedagógico. No sentido estético, repercute nos sujeitos do contexto áulico, não se vinculando ao dualismo feio e bonito, mas marcando, significativamente, e sinalizando para a harmonia que evoca a criatividade. Entretanto, também importa que se pense no quanto essa organização incide sobre o deslocamento ao possibilitar uma visualização ampliada da turma ao realizar as atividades e ao aproximar os atores da cena áulica. Não deve, ainda, camuflar a agitação que gera, pois aprender pressupõe atividade, movimento. Quando se pensa, questiona-se, discute-se em um universo com muitos sujeitos. Logo há de se ter o espaço aberto para tais comportamentos, afinal, ensinar e aprender pode ser uma aventura intelectual, destituída de tabu, rumo à emancipação (Rancière, 2011). Como nos diz a professora:

\footnotetext{
Os grupos áulicos provocam grandes mudanças. Mais que social é uma mudança que incide no ser humano, pois permite perceber o aprendizado para todos e chega a todos quando conseguimos fazer um bom trabalho que articule todas as variáveis, um trabalho em rede. Ao mesmo tempo em que é possível, é prazeroso e trabalhoso. Mesmo assim, ficamos felizes de poder contribuir com a educação de qualidade (Transcrição de Entrevista, 9/12/2012).
}

Cabe ressaltar que pensar na sala de aula por meio dessa organização tem o objetivo de concretizar, no cotidiano escolar, a ideia central de que as aprendizagens se dão na relação dialógica e dialética entre pares. Além disso, os grupos áulicos organizam o espaço da sala de aula retra- tando a construção de uma nova estética e traçam metas voltadas à aprendizagem da leitura e da escrita.

Os grupos áulicos como procedimento didático provocam uma nova postura que investe no princípio da igualdade das inteligências e no potencial criativo, tanto do professor quanto do aluno para que, assim, seja possível transitar nesse universo com ousadia e superar as expectativas, como Jacotot (Rancière, 2011), ao assumir o risco e permitir a si e ao aluno atuar de forma diferenciada. Ele introduziu situações para que os alunos, sozinhos, encontrassem soluções e aprendessem. Assim, percebe-se que os grupos configurados por meio da eleição na sala de aula e o grupo de estudo semanal do qual os professores participam são ações que possibilitam o diálogo, a discussão, o pensamento entre pares em direção a novos conhecimentos que venham a ressignificar o ser professor e o ser aluno e, consequentemente, a aula, na sua estrutura e nas relações, ao torná-la um espetáculo:

Coordenar uma boa aula é ser capaz de produzir um bom espetáculo. Um espetáculo que encante, que emocione, que prenda, que leve a pensar. Uma experiência imperdível e impossível de ser recuperada em sua graça e forças únicas para quem dela participou, ao vivo e a cores (Grossi, 2010, p. 47).

Portanto, a organização do espaço pedagógico na lógica dos grupos áulicos abre espaço para que os alunos tenham oportunidades de se relacionar com o maior número de pares e diferenças, percebendo outras perspectivas culturais a serem aproveitadas na própria trajetória rumo à leitura e à escrita. Dessa forma, instaura-se o debate para a construção de novos conceitos e a possibilidade de ampliação e de transformação das primeiras aquisições culturais para a construção de novas concepções de si mesmo e do mundo (Vygotsky, 1994; 2000).

\section{Considerações Finais}

O objetivo principal deste artigo foi evidenciar as contribuições dos grupos áulicos no processo de aprendizagem entre pares por meio de observação participante, análise documental e entrevista não estruturada.

Percebe-se que a cena áulica é entremeada por relações socioculturais que dinamizam o processo de ensino e de aprendizagem e que tal disposição organiza o cenário de forma a estruturar o encadeamento das aulas, o que nos leva à reflexão do quanto esse contexto faz diferença, provoca e potencializa a capacidade de todos nesse espaço que se configura para pensar e para sentir.

A organização da sala em grupos áulicos traz uma nova conformação que permite imprimir ritmo, tanto à atuação do professor, quanto à do aluno na resolução das situações didáticas propostas. Contribui, ainda, para que todos se vinculem de alguma forma, além de garantir uma visão geral de toda a turma organizada em grupos, identificados 
por nomes e territórios que ocupam na sala. Neste sentido, constrói-se cumplicidade; a professora se compromete com todos e cada um entre si, em uma relação de corresponsabilidade com a aprendizagem de todos.

Os resultados deste estudo contribuem para o avanço das investigações em torno da aprendizagem com os pares ao revelar as potencialidades dos grupos áulicos para o desenvolvimento dos estudantes em processo de alfabetização. Como limitação, destaca-se a não existência de pesquisas científicas sobre este procedimento didático, o que impediu uma análise comparativa da efetividade deste procedimento para o incremento da aprendizagem com os pares.

\section{Referências}

Abatti, R., Villas-Boas, S., \& Cabral, A. V. B. (2010). Grupos áulicos. Em A. L. C. Rocha (Org.), A interação social na sala de aula: grupos áulicos ( $2^{\mathrm{a}}$ ed., pp. 83-96). Porto Alegre: Geempa.

Alves-Mazzotti, A. J., \& Gewandsznajder, F. (2002). O método nas ciências naturais e sociais: pesquisa quantitativa e qualitativa $\left(2^{\mathrm{a}}\right.$ ed.). São Paulo: Pioneira Thomson Learning.

Bruner, J. S. (1975). Uma nova teoria de aprendizagem (3ª ed.) (N. L. Ribeiro, Trad.). Rio de Janeiro: Bloch Educação.

Caon, J. L. (2010). Relatos de experiências. Em A. L. C. Rocha (Org.), A interação social na sala: grupos áulicos ( $2^{\mathrm{a}}$ ed., pp. 97100). Porto Alegre: Geempa.

Geempa (2010). Aula-entrevista: caracterização do processo rumo à leitura e escrita. Porto Alegre: Geempa.

Geertz, C. (1978). A interpretação das culturas. Rio de Janeiro: Editora Guanabara.

Grossi, E. P. (2005). Uma arqueologia dos saberes do Geempa. Em Revista do Geempa - Todos podem aprender: qual é a chave? Porto Alegre, 10, set. p.11-40.

Grossi, E. P. (2010). Didática do nível silábico (11a ed.). Rio de Janeiro: Paz e Terra.

Keil, I. M. (1995). Ciladas e armadilhas no caminho da escola. Em E. P. Grossi (Org.), Celebração do conhecimento na aprendizagem: Geempa 25 anos (pp. 89-98). Porto Alegre: Sulina.

Kohan, W. O. (2005). Infância. Entre educação e filosofia. Belo Horizonte: Autêntica.
Pain, S. (2009). Subjetividade e objetividade: relação entre desejo e conhecimento. Petrópolis, RJ: Vozes. (Transcrição do curso Subjetividade e Objetividade).

Piaget, J. (2004). Seis estudos de psicologia. (24a ed., M. A. M. D’Amorim, \& P. S. L. Silva, Trad.) Rio de Janeiro: Forense Universitária.

Piaget, J., \& Grêco, P. (1974). Aprendizagem e conhecimento. (Equipe da Livraria Freitas Bastos, Trad.) Rio de Janeiro: Livraria Freitas Bastos.

Rancière, J. (2011). O mestre ignorante: cinco lições sobre emancipação intelectual ( $3^{a}$ ed., L. Valle, Trad.). Belo Horizonte: Autêntica Editora.

Rocha, A. L. C. (2005). A urdidura das trocas sociais na trama das aprendizagens escolares. Em Geempa (Org.), Textos Geempianos, 01 (p.33). Porto Alegre: Ed. GEEMPA.

Psicologia (Org.), Resumos de comunicações científicas, XXII Reunião Anual de Psicologia (p. 66). Ribeirão Preto: SBP.

Rocha, A. L. C., \& Vedana, V. (2010). Revisitando o processo de organização de grupos áulicos à luz da teoria geempiana de sala de aula. Em A. L. C. Rocha (Org.), A interação social na sala de aula: grupos áulicos (2a ed., pp. 101-132). Porto Alegre: Geempa.

Rogoff, B. (2005). A natureza cultural do desenvolvimento humano. Porto Alegre: Artes Médicas.

Vergnaud, G. (2003). A gênese dos campos conceituais. Em E. P. Grossi (Org.), Por que ainda há quem não aprende? A teoria. Petrópolis-RJ: Vozes.

Vygotsky, L. S. (1994). A formação social da mente: o desenvolvimento dos processos psicológicos superiores. ( $5^{\mathrm{a}}$ ed., J. C. Neto, L. S. M. Barreto, \& S. C. Afeche, Trad.) São Paulo: Martins Fontes.

Vygotsky, L. S. (2000). A construção do pensamento e da linguagem. (P. Bezerra, Trad.) São Paulo: Martins Fontes.

Wallon, H.H. (1989). As origens do pensamento na criança. (D. S. Pinheiro, \& F. Braga, Trad.) São Paulo: Manole.

Wallon, H.H. (1995). A evolução psicológica da criança. (C. Carvalho, Trad.). Lisboa: Edições 70.
Recebido em: 18/09/2013

Reformulado em: 10/04/2014

Aprovado em: 16/05/2014 


\section{Sobre as autoras}

Nair Cristina da Silva Tuboiti (ncstuboiti@gmail.com)

Mestre em Psicologia, Secretaria de Educação do Distrito Federal.

Lêda Gonçalves de Freitas (ledag@ucb.br)

Doutora em Psicologia Social e do Trabalho, Universidade Católica de Brasília. 